\title{
Spectroscopic investigations of molecular association of cyclophanes with anthracene
}

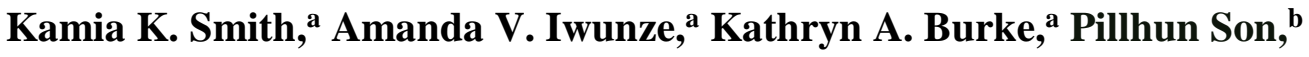 \\ and M. Thandi Buthelezi ${ }^{\mathrm{a}}$ \\ ${ }^{a}$ Chemistry Department, Wheaton College, Norton, MA 02766 USA \\ ${ }^{b}$ Department of Chemistry and Biochemistry, Texas Tech University, Lubbock, Texas 79409, \\ USA \\ E-mail: buthelezi_thandi@wheatoncollege.edu
}

\section{In honor of Professor Richard A. Bartsch on the occasion of his $\mathbf{7 0}^{\text {th }}$ birthday}

DOI: http://dx.doi.org/10.3998/ark.5550190.0011.714

\begin{abstract}
We report an improved synthesis method for the production of cyclophanes $\mathbf{5}, \mathbf{6}$, and $\mathbf{7}$ in higher yields of 71,98, and 99\%, respectively, compared to the previously reported 40, 30, and 70\% yields, respectively. Cyclophanes $\mathbf{C 5}, \mathbf{C 6}$, and $\mathrm{C7}$, called corrals, have different cavity sizes determined by the number of methylene spacers varying from three to five; they form inclusion complexes with neutral aromatic molecules. Therefore, we have studied their interactions with anthracene (A) using absorption, fluorescence, and Fourier transform infrared spectroscopies. The average association constants of each cyclophane with anthracene in dichloromethane were determined to be $(\log \mathrm{K})$ $4.24 \pm 0.10,4.81 \pm 0.05$, and $4.25 \pm 0.03$ for the C5/A, C6/A, and C7/A systems, respectively. The binding of anthracene is favored by C6 over C5 and C7 in solution, possibly due to increased stability of the equilibrium geometry of the C6/A complex. Upon complexation low frequency spectral shifts for several transitions associated with anthracene and corral molecules were observed. The slight spectral shifts are in accord with weak intermolecular forces prevalent in the studied corral/anthracene complexes.
\end{abstract}

Keywords: Host/guest complexes, anthracene, cyclophane synthesis, UV-vis absorption, and fluorescence spectroscopy

\section{Introduction}

Cyclophanes form inclusion complexes - host/guest—with charged and neutral molecules. ${ }^{1-6}$ Host/guest interactions play an important role in biochemical systems and the environment. The study of host/guest interaction of cyclophane/neutral compounds spanned the past three 
decades $^{5,7}$; however, the structure-function of noncovalently bound interactions is still not yet completely understood.

In this paper, we report host/guest interactions of recently synthesized cyclophanes-corrals 5, 6, and 7-with anthracene. Corrals 5-7 have different cavity sizes determined by the number of methylene groups in the spacers (n) varying from three to five (Figure 1). A crystal structure of the complex of corral 7 with anthracene indicating inclusion complexation in the solid phase has been reported. ${ }^{3}$ Selective binding of an aromatic molecule by a corral molecule to form an inclusion host/guest complex, Figure 2, is governed by the nature of the interacting species. ${ }^{4}$ Corral cavity size, the medium, and the temperature play vital roles in the binding capabilities of corrals. Anthracene interacts with corrals 5-7 and forms 1:1 host/guest complexes that are characterized in solution and in the solid phase.

In the current investigation, absorption and fluorescence titrations are employed in the study of solution phase systems. Attenuated Total Reflection Fourier-infrared (ATR-FTIR) spectroscopy is used to investigate the solid phase systems. Equilibrium constants, K, for the binding of corrals and anthracene in $\mathrm{CH}_{2} \mathrm{Cl}_{2}$, and vibrational frequencies of the solid phase corral/anthracene complexes are presented.

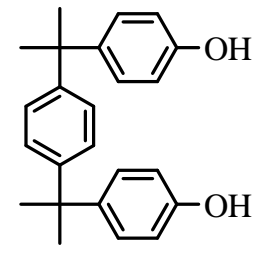

1

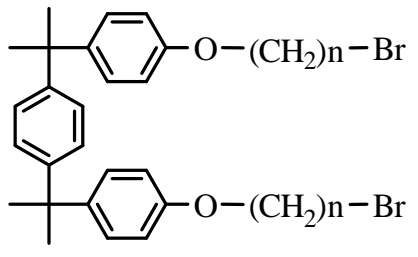

$2 \frac{\mathrm{n}}{3}$

34

45

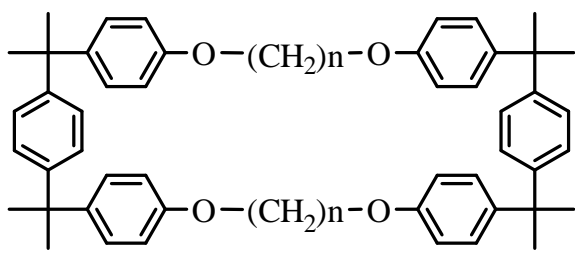

$5 \frac{\mathrm{n}}{3}$

64

75

Figure 1. Starting material and intermediates used for the syntheses of corrals 5-7.

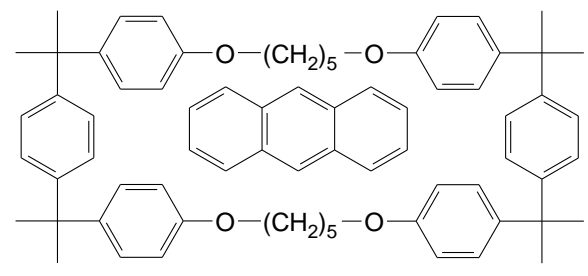

(a)

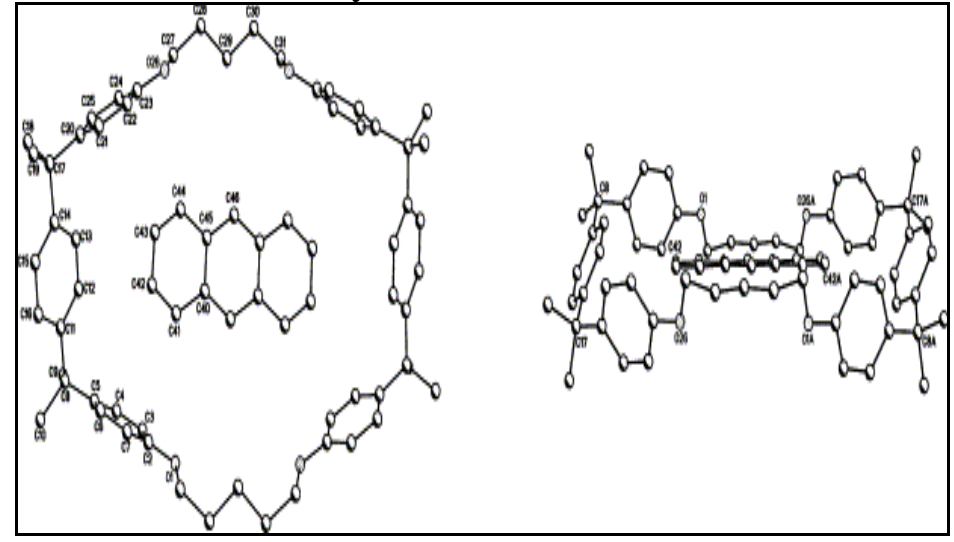

(b)

Figure 2. (a) Two-dimensional structural representation of the 1:1 inclusion Corral 7/Anthracene (C7/A) complex. (b) Three-dimensional top and side views of the crystal structure of C5/A, hydrogen atoms have been omitted for clarity. ${ }^{3}$ 


\title{
Results and Discussion
}

\section{Corrals synthesis}

Cyclophanes 5-7 were prepared in two steps from commercially available $\alpha, \alpha$ '-di(hydroxyphenyl)1,4-diisopropylbenzene $\mathbf{1}$. Reaction of $\mathbf{1}$ with seven equivalents of the appropriate 1, $\omega$ dibromoalkane and finely ground $\mathrm{K}_{2} \mathrm{CO}_{3}$ in $\mathrm{MeCN}$ gave the intermediate dibromides 2-4. Whereas previous reported procedures used silica gel chromatography ${ }^{1}$ for purification and also employed slightly impure intermediates for the next step, ${ }^{2}$ an improved method of recrystallization from hexanes gave pure products in 61, 90 and 60\% yields for the intermediate dibromides 2, 3 and $\mathbf{4}$, respectively. Another modification in the procedure compared to the previous reported methods ${ }^{1-3}$ was that the corresponding 1, $\omega$-dibromoalkane was added to the reaction mixture 1.5 hours after bisphenol 1 had been refluxing with the base, as opposed to beginning the reaction with all reagents present at the outset.

Cyclization was achieved by reacting equivalent amounts of the appropriate dibromide with bisphenol 1 and cesium carbonate in DMF, which gave 71, 32 and 99\% yields for the cyclophanes $\mathbf{5}$, $\mathbf{6}$ and 7, respectively. Since the yield of cyclophane $\mathbf{6}$ was significantly lower than those for $\mathbf{5}$ and $\mathbf{7}$, the procedure was modified by adding the dibromide $\mathbf{3}$ and bisphenol $\mathbf{1}$ simultaneously via a syringe pump over a 5-hour period. This gave a $98 \%$ yield of $\mathbf{6}$ which is a marked increase in the previously reported $30 \%$ yield. ${ }^{1}$ Instead of using silica gel chromatography ${ }^{1-3}$ for purification, a solvent wash with hexanes, a solvent wash with $\mathrm{MeOH}$, and recrystallization from $\mathrm{CH}_{2} \mathrm{Cl}_{2}-\mathrm{MeOH}$ for $\mathbf{5}, \mathbf{6}$ and 7, respectively, were found to be a simpler purification method giving pure products in high yields of 71, 98 and 99\%, respectively, compared to the previously reported 40, 30 and $70 \%$ yields.

\begin{abstract}
Absorption titrations
Absorption spectra of anthracene, Corral 6 (C6) and the C6/A complex are shown in Figure 3. Molar absorptivities of corrals 5-7 and anthracene in dichloromethane were determined using Beer-Lambert's law and are summarized in Table 1. Absorption spectra of unbound and bound anthracene for the C6/A system (Figure 4) indicate absorption bands associated with each molecule. The presence of bands arising from both $\mathrm{C} 6$ and anthracene in the spectrum of the complex suggest that a C6/A complex may have formed. An increase in the concentration of C6 causes its absorption band $\left(\lambda_{\max }=278 \mathrm{~nm}\right)$ to increase in accordance with Beer's law while the anthracene absorption bands in the wavelength range 320-390 $\mathrm{nm}$ decrease possibly due to complexation. However, in our earlier studies ${ }^{4}$ for the formation of the C7/A complex we reported an increase in the anthracene absorption bands between $320-390 \mathrm{~nm}$ as a function of the concentration of C7. In this study, we observed that C5/A system behaves similarly to C7/A in solution. These observations suggest that the ground state complex of C6/A may have a different geometry compared to the structures of C5/A and C7/A complexes in the liquid phase.
\end{abstract}




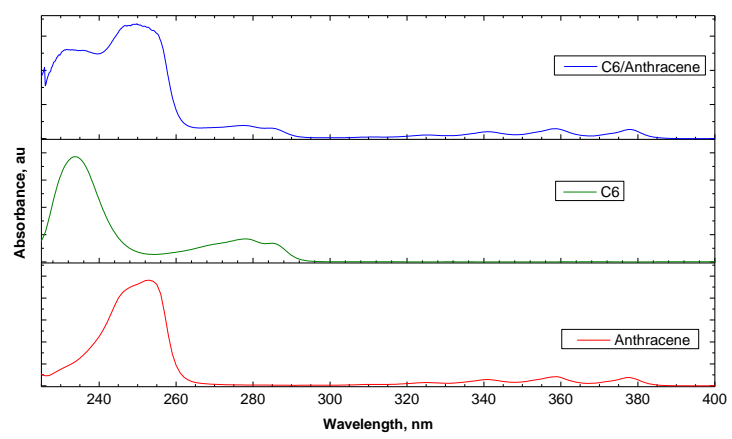

Figure 3. Absorption spectra of anthracene, C6, and $\mathrm{C6} / \mathrm{A}$ complex in $\mathrm{CH}_{2} \mathrm{Cl}_{2}$ at $25{ }^{\circ} \mathrm{C}$.

Table 1. Molar absorptivities of anthracene and corrals in $\mathrm{CH}_{2} \mathrm{Cl}_{2}$ at $25^{\circ} \mathrm{C}$

\begin{tabular}{|c|c|c|c|}
\hline Substance & $\begin{array}{c}-\left(\mathrm{CH}_{2}\right) \mathrm{n}- \\
\mathrm{n}\end{array}$ & $\begin{array}{c}\text { Absorption } \\
\left(\lambda_{\max }, \mathrm{nm}\right)\end{array}$ & $\begin{array}{c}\text { Molar Absorptivity } \\
\left(\mathrm{M}^{-1} \cdot \mathrm{cm}^{-1}\right)\end{array}$ \\
\hline Anthracene $^{\mathrm{a}}$ & - & 325 & 2800 \\
& & 358 & 7500 \\
\hline Corral 5 & 3 & 277 & 8650 \\
\hline Corral 6 & 4 & 278 & 8800 \\
& & 284 & 7100 \\
\hline Corral 7 & 5 & 278 & 8400 \\
& & 285 & 6800 \\
\hline
\end{tabular}

${ }^{\text {aD }}$ ata taken from reference 4.

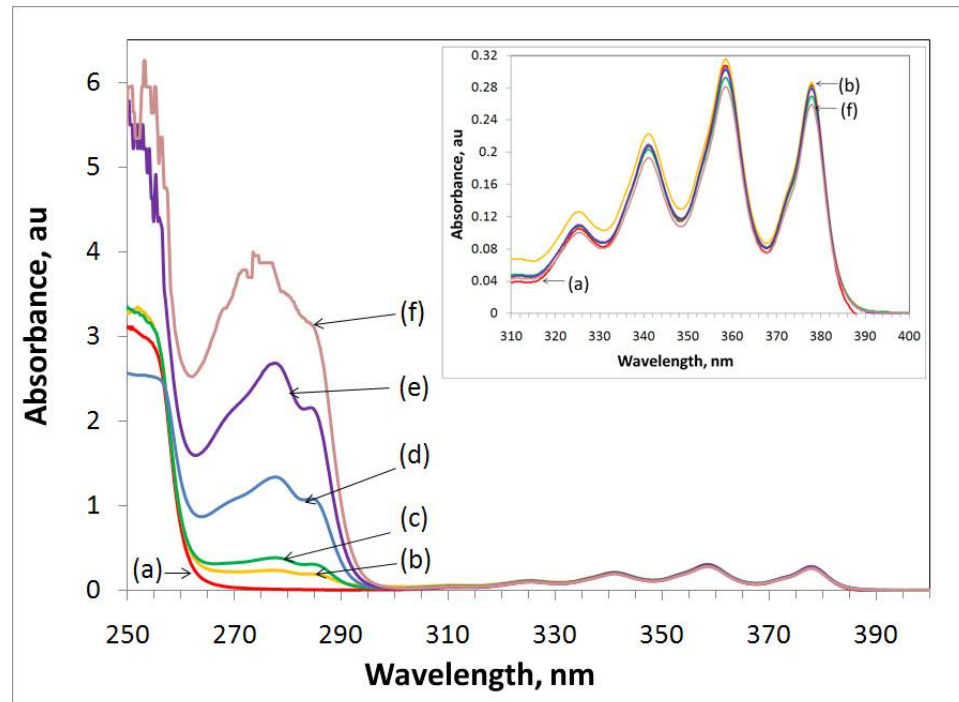

Figure 4. Effect of increasing concentration of corral 6 on the absorption spectrum of anthracene in $\mathrm{CH}_{2} \mathrm{Cl}_{2}$. (a) $2.5 \times 10^{-5} \mathrm{M}$ anthracene and fixed in all solutions and [C6] was varied: (b) $5 \times 10^{-6}$ $\mathrm{M}$, (c) $2.5 \times 10^{-5} \mathrm{M}$, (d) $8 \times 10^{-5} \mathrm{M}$, (e) $2.5 \times 10^{-4} \mathrm{M}$, and (f) $5 \times 10^{-4} \mathrm{M}$. 


\section{Fluorescence titrations}

In all three systems - C5/A, C6/A, and C7/A - the anthracene fluorescence is quenched by the presence of the corral molecule (Figure 5). Isostilbic points were observed in all three systems suggesting the presence of only two absorbing species in equilibrium, in accordance with 1:1 complexation between each corral and anthracene. Fitting of the fluorescence spectral data at specific wavelengths to the equation of Bourson, et al. ${ }^{8}$ (Figure 6) yielded average association constants $(\log \mathrm{K})$ of $4.24 \pm 0.10,4.81 \pm 0.05$, and $4.25 \pm 0.03$ for the C5/A, C6/A, and C7/A systems, respectively (Table 2). The concentration of anthracene was kept contant at $2.5 \times 10^{-5}$ $\mathrm{M}$ in all systems. The results indicate that inclusion complexation of anthracene by corral $\mathbf{6}$ is favored over inclusion complexation of anthracene by corrals $\mathbf{5}$ and $\mathbf{7}$.

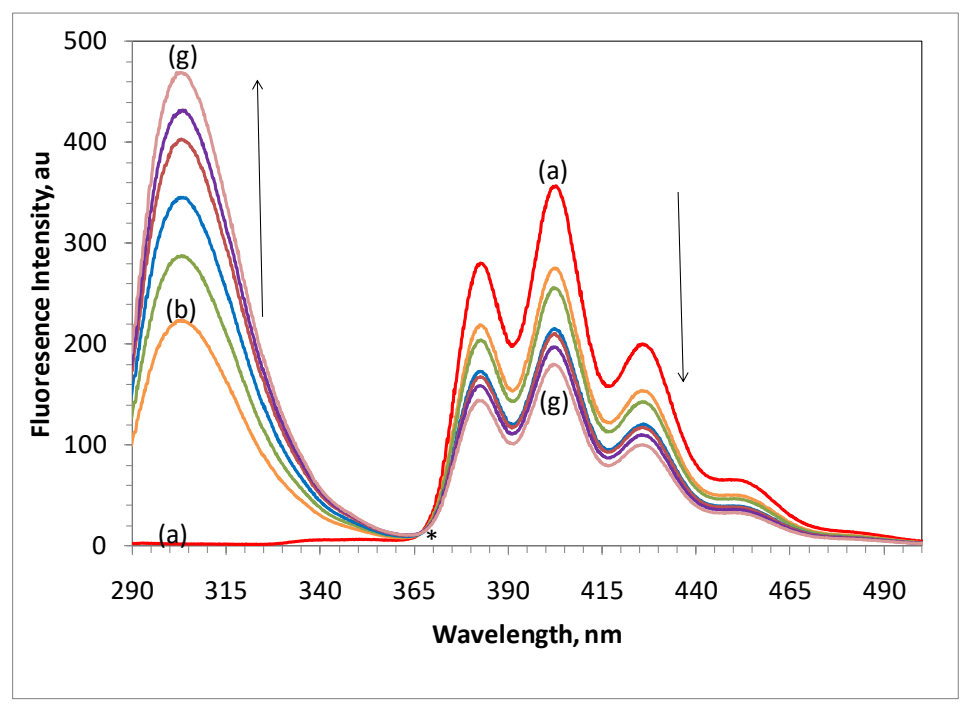

Figure 5. Effect of increasing concentration of corral 6 on the fluorescence spectrum of anthracene in $\mathrm{CH}_{2} \mathrm{Cl}_{2}$. (a) $2.5 \times 10^{-5} \mathrm{M}$ anthracene and fixed in all solutions and $\mathrm{C6}$ was varied: (b) $5 \times 10^{-6} \mathrm{M}$, (c) $1 \times 10^{-5} \mathrm{M}$, (d) $2 \times 10^{-5} \mathrm{M}$, (e) $3 \times 10^{-5} \mathrm{M}$, (f) $4 \times 10^{-5} \mathrm{M}$, and (g) $5 \times 10^{-5} \mathrm{M}$. Excitation wavelength was $278 \mathrm{~nm}$. The asterisk indicates the isostilbic point. 


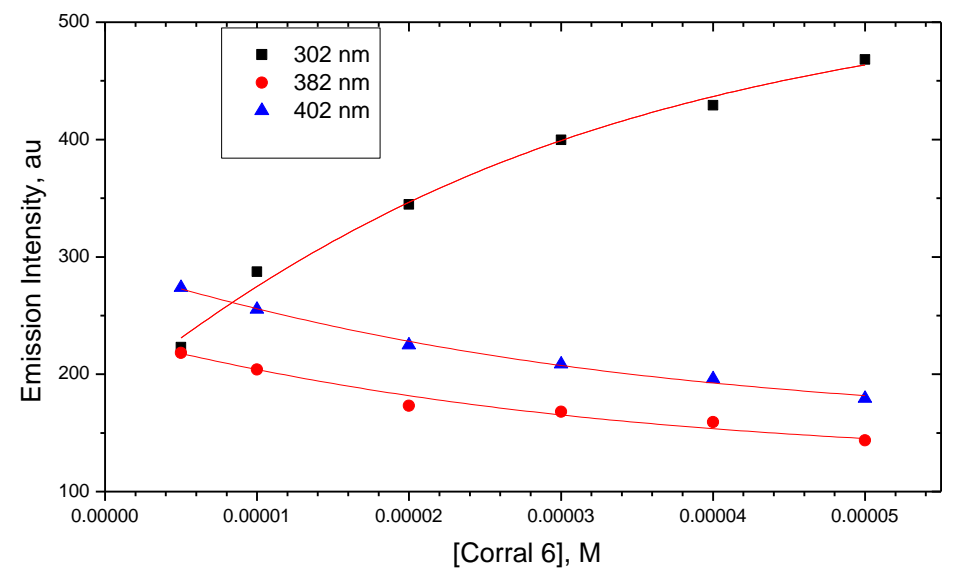

Figure 6. Non-linear regression analysis (line) of the fluorescence spectral data (symbols) for C4/A complex $\mathrm{CH}_{2} \mathrm{Cl}_{2}$ at 302, 382, and $402 \mathrm{~nm}$ according to the Bourson equation. ${ }^{8}$ Emission intensities obtained from Figure 5.

Table 2. Stability constants, $\log \mathrm{K}$, of corral/anthracene systems in $\mathrm{CH}_{2} \mathrm{Cl}_{2}$ at $25^{\circ} \mathrm{C}$

\begin{tabular}{|c|c|c|c|c|}
\hline System & $\begin{array}{c}\lambda_{\text {abs max }} \\
\mathrm{nm}\end{array}$ & $\begin{array}{c}\lambda_{\text {em, max }}{ }^{\mathrm{a}} \\
\mathrm{nm}\end{array}$ & $\log \mathrm{K}$ & $\begin{array}{l}\text { Equilibrium } \\
\text { fit, } \mathrm{R}^{2} \text { value }\end{array}$ \\
\hline \multirow[t]{3}{*}{$\mathrm{C} 5 / \mathrm{A}$} & \multirow[t]{3}{*}{378} & & $4.30 \pm 0.05$ & 0.962 \\
\hline & & 382 & $4.14 \pm 0.01$ & 0.977 \\
\hline & & 402 & $4.27 \pm 0.02$ & 0.963 \\
\hline \multirow[t]{3}{*}{$\mathrm{C} 6 / \mathrm{A}^{\mathrm{b}}$} & & 302 & $4.83 \pm 0.03$ & 0.993 \\
\hline & & 382 & $4.80 \pm 0.05$ & 0.972 \\
\hline & & 402 & $4.80 \pm 0.05$ & 0.995 \\
\hline \multirow[t]{4}{*}{$\mathrm{C} 7 / \mathrm{A}^{\mathrm{c}}$} & \multirow[t]{4}{*}{325} & & $4.21 \pm 0.1$ & 0.999 \\
\hline & & 382 & $4.24 \pm 0.2$ & 0.999 \\
\hline & & 403 & $4.28 \pm 0.1$ & 0.999 \\
\hline & & 427 & $4.27 \pm 0.2$ & 0.990 \\
\hline
\end{tabular}

${ }^{a}$ Excitation wavelength for the C/A systems was at $278 \mathrm{~nm}$.

${ }^{\mathrm{b}}$ Absorption data for $\mathrm{C} 6 / \mathrm{A}$ could not be determined as the absorption peaks of the spectra in the region of interest 320-400 $\mathrm{nm}$ coalesced, Figure 5.

${ }^{\mathrm{c}}$ Data taken from reference 4.

\section{Vibrational structure analysis of solid phase C/A complexes}

Crystals of corral/anthracene complexes were prepared by dissolving 1:1 corral:anthracene mole ratio in a minimal amount of heated 1:1 (by volume) solution of $\mathrm{CHCl}_{3}-\mathrm{CH}_{2} \mathrm{Cl}_{2}$. All corral/anthracene $\mathrm{KBr}$ pellet vibrational spectra were acquired from crystals grown using the initial samples ${ }^{2}$ of corrals 5-7 and a 1:1 corral/anthracene mole ratio. The ATR-FTIR spectra 
were obtained from samples that were prepared with the newly synthesized corrals 5-7, described in this paper. The C/A complexes used to acquire the ATR spectra were prepared with 1:2 corral/anthracene mole ratio in a heated solution of 1:1:2 (by volume) solution of $\mathrm{CHCl}_{3}$ $\mathrm{CH}_{2} \mathrm{Cl}_{2}-\mathrm{MeCN}$.

The acquired spectrum of unbound anthracene (Figure 7) demonstrates that the ATR-FTIR technique can provide repeatable data that match literature values ${ }^{9,10}$ and are comparable to the $\mathrm{KBr}$ pellet data. The FTIR spectra of the newly synthesized and previous ${ }^{2}$ corrals are identical suggesting that the compounds are the same. The vibrational spectra of the three C/A systemsC5/A, C6/A, and C7/A-in Figures 8-10 indicate different spectra for the isolated anthracene, corral, and corral/anthracene complexes. Peak positions of the C/A complexes include peaks associated with individual units - anthracene and each corral—with minimal or no spectral shift. Spectral shifts upon complexation were in the range of $2-10 \mathrm{~cm}^{-1}$ because of weak intermolecular forces prevalent in the studied corral/anthracene complexes. The largest spectral shifts observed were associated with the out-of-plane C-H bending modes of anthracene at 726 and $884 \mathrm{~cm}^{-1}$, and corrals 5-7 at $826 \mathrm{~cm}^{-1}$. Decreased intensities were observed for the complexes possibly due to changes in the dipole moment upon complexation.

Vibrational spectra- $\mathrm{KBr}$ pellet data - suggest that structures of C5/A and C7/A are similar in the solid phase based on spectral similarities. This observation is in agreement with absorption and fluorescence results in Table 2, where the binding of C5/A and C7/A are similar ( $\log \mathrm{K} \sim 4.2$ ) and that of C6/A is favored ( $\log \mathrm{K} \sim 4.8)$.

The ATR vibrational spectra were acquired with newly synthesized corrals. Observed similarities in the ATR spectra of C6/A and C7/A are unexpected. Single crystal X-ray structural analyses of these complexes to determine their geometries in the solid phase are in progress.

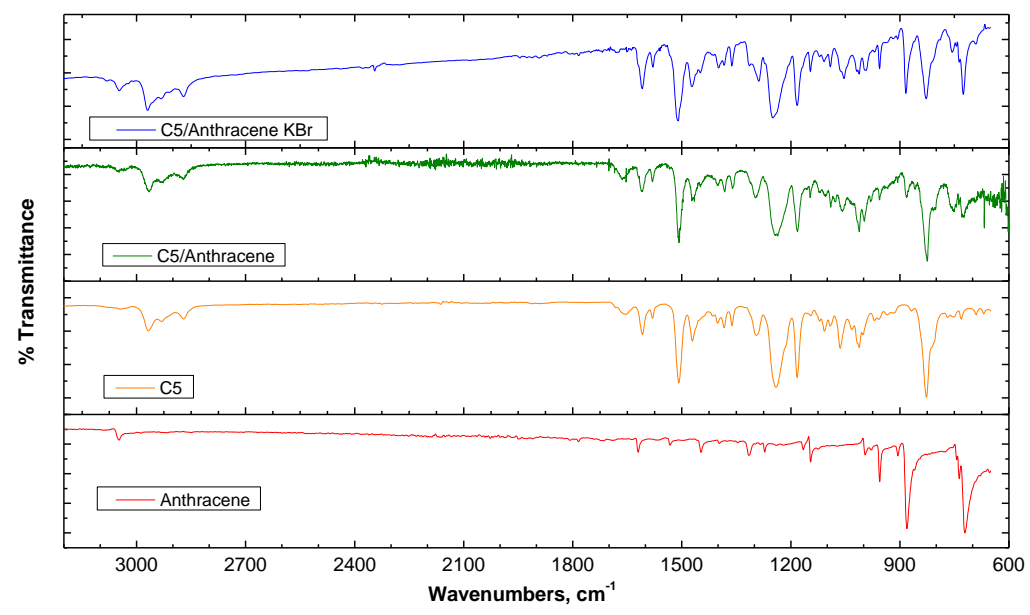

Figure 8. ATR-FTIR vibrational spectra of anthracene, $\mathrm{C} 5$ and C5/A in the solid phase and FTIR spectrum of $\mathrm{C} 5 / \mathrm{A}$ complex obtained using a $\mathrm{KBr}$ pellet. 


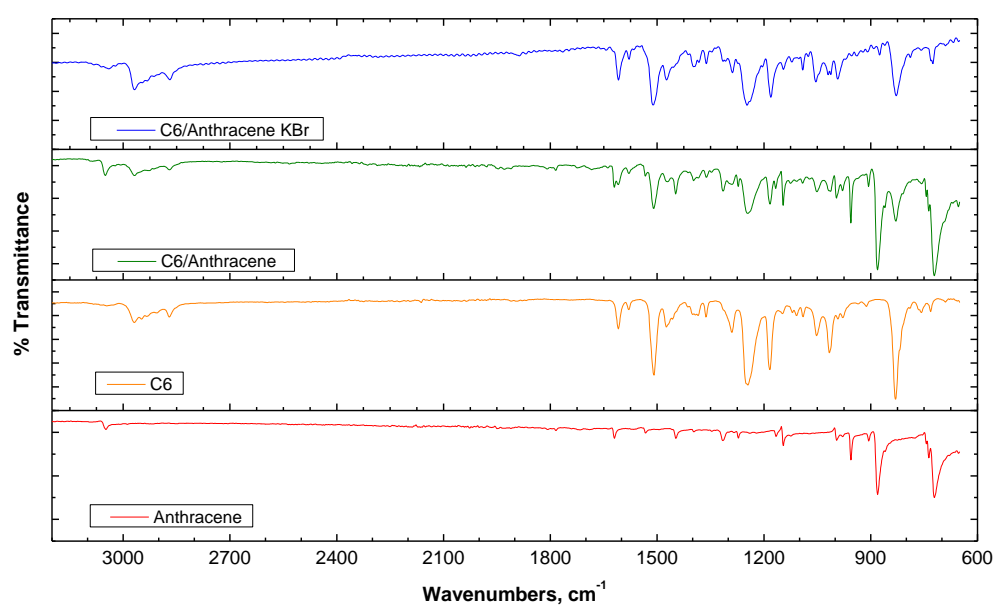

Figure 9. ATR-FTIR vibrational spectra of anthracene, C6 and C6/A in the solid phase and FTIR spectrum of $\mathbf{C 6 / A}$ complex obtained using a $\mathrm{KBr}$ pellet.

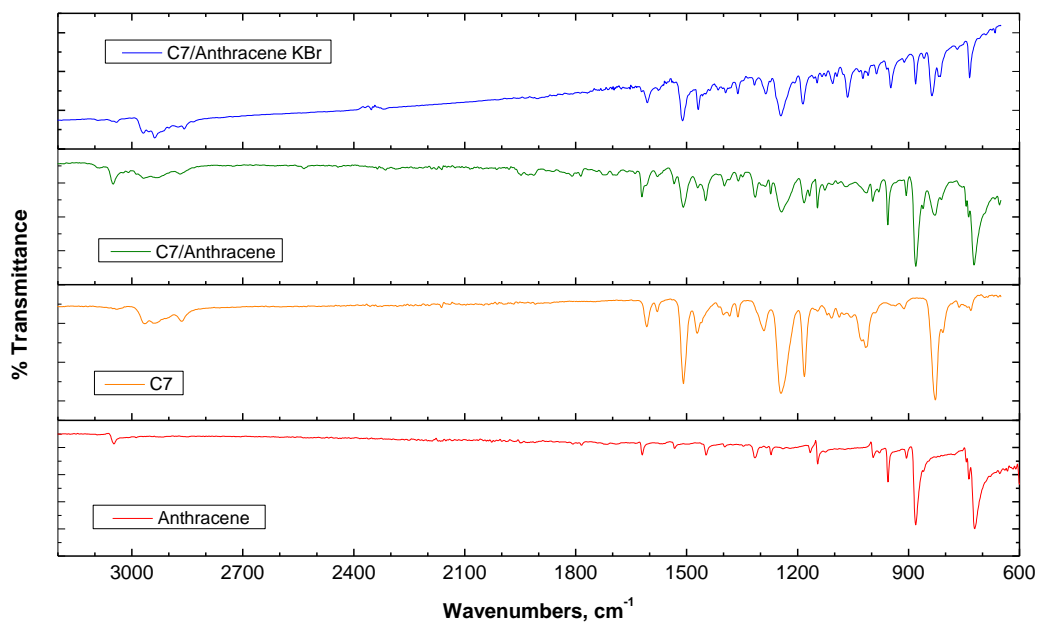

Figure 10. ATR-FTIR vibrational spectra of anthracene, $C 7$ and C7/A in the solid phase and FTIR spectrum of C7/A complex obtained using a KBr pellet.

\section{Molecular modeling}

The calculated vibrational spectra (Figure 11) of the of the gas phase anthracene, corrals 5-7, C5/A, C6/A, and C7/A systems using the Gaussian 03W PM3MM semi-empirical method ${ }^{11}$ yielded vibrational spectra similar to the solid phase experimental spectra. Moreover, the predicted gas phase geometries (Figure 12) of C5/A and C7/A are similar with the anthracene guest molecule coplanar with the corral molecule in agreement with experimental observations in the liquid and solid phases. 


\section{Conclusions}

An improved method for the synthesis of corrals 5-7 with high yields in the range of 70-99\% is reported. Binding studies of these corrals with anthracene reveal that corral $\mathbf{6}$ forms the most stable complex. Molecular modeling and experimental observations suggest that the structures of C5/A and C7/A are similar, possibly with the anthracene molecule in the same plane as the corral molecule. Molecular modeling predicts that the anthracene guest lies perpendicular to the plane of corral 6, in the gas phase C6/A complex (Figure 12).

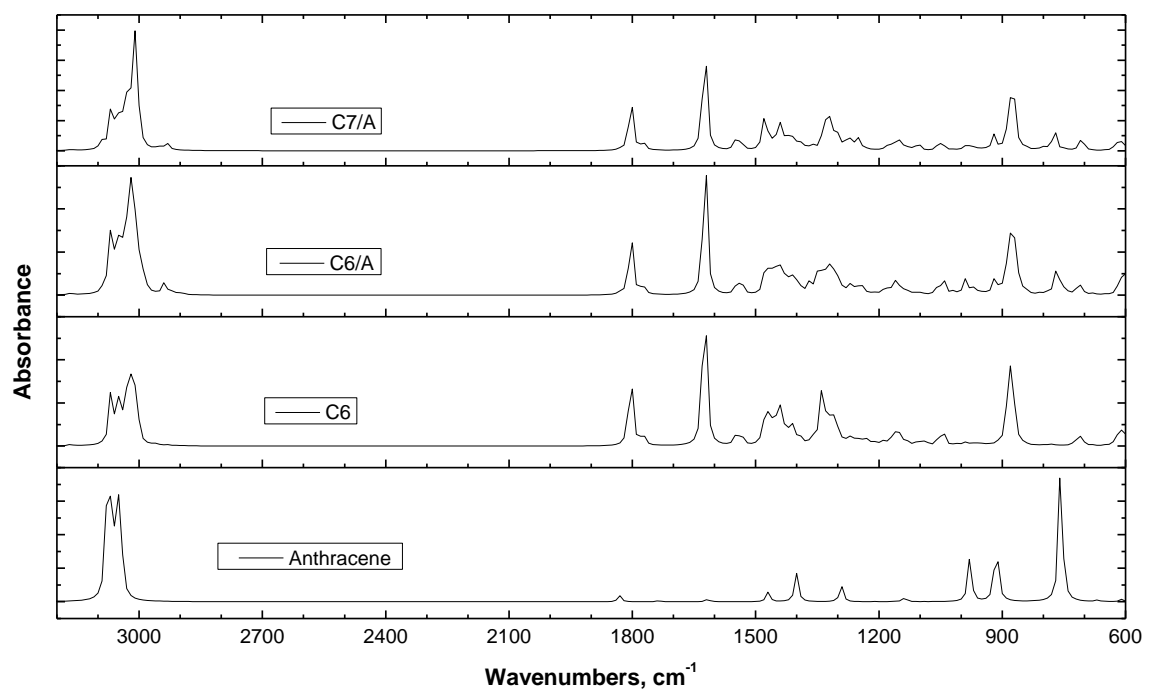

Figure 11. Simulated gas phase vibrational spectra of anthracene, C6, C6/A and C7/A complexes using Gaussian 03W semi-empirical PM3MM method.

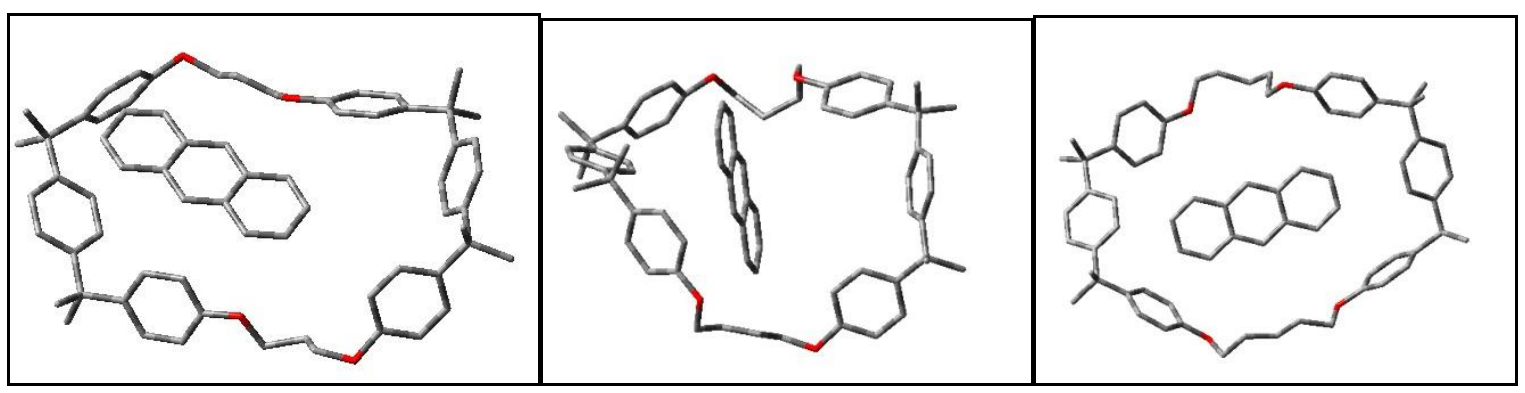

Figure 12. Optimized gas phase structures (from left to right) of $\mathrm{C} 5 / \mathrm{A}, \mathrm{C} 6 / \mathrm{A}$, and C7/A complexes using Gaussian 03W semi-empirical PM3MM method. 


\section{Experimental Section}

\section{Corral synthesis}

$\boldsymbol{\alpha}, \boldsymbol{\alpha}$ '-Di[(3-bromo-1-propoxy)phenyl]-1,4-diisopropylbenzene (2). A mixture of 1 (5.00 g (14.5 $\mathrm{mmol})$ and $10.00 \mathrm{~g}(72.5 \mathrm{mmol})$ of finely ground $\mathrm{K}_{2} \mathrm{CO}_{3}$ in $\mathrm{MeCN}(200 \mathrm{~mL})$ was refluxed for 1.5 hours. Then 1,3-dibromopropane $(10.3 \mathrm{~mL}, 101 \mathrm{mmol})$ was added and the mixture was refluxed for another 30 hours. The MeCN was evaporated in vacuo and $\mathrm{CH}_{2} \mathrm{Cl}_{2}$ was added to the residue. The solution was washed with $5 \%$ aq. $\mathrm{HCl}(250 \mathrm{~mL})$, dried over $\mathrm{MgSO}_{4}$, and evaporated in vacuo. The crude product was recrystallized from hexanes to give $5.22 \mathrm{~g}(61 \%)$ of the desired compound 2 with mp $70-71{ }^{\circ} \mathrm{C} .{ }^{1} \mathrm{H}$ NMR $\left(500 \mathrm{MHz}, \mathrm{CDCl}_{3}\right) \delta_{\mathrm{H}}: 1.64\left(\mathrm{~s}, 12 \mathrm{H}, \mathrm{CH}_{3}\right), 2.30(\mathrm{q}, J=$ $\left.6.0 \mathrm{~Hz}, 4 \mathrm{H}, \mathrm{CH}_{2}\right), 3.60$ (t, $\left.J=6.5 \mathrm{~Hz}, 4 \mathrm{H}, \mathrm{CH}_{2}\right), 4.08\left(\mathrm{t}, J=5.5 \mathrm{~Hz}, 4 \mathrm{H}, \mathrm{CH}_{2}\right), 6.78-6.84(\mathrm{~m}, 4 \mathrm{H}$, $\mathrm{ArH}), 7.08-7.18(\mathrm{~m}, 8 \mathrm{H}, \mathrm{ArH}) .{ }^{13} \mathrm{C} \mathrm{NMR}\left(126 \mathrm{MHz}, \mathrm{CDCl}_{3}\right) \delta_{\mathrm{C}}: 30.1,30.9,32.4,41.8,65.1$. 113.8, 126.2, 127.7, 127.8, 143.2, 147.8, 156.4. Anal. Calcd for $\mathrm{C}_{30} \mathrm{H}_{36} \mathrm{Br}_{2} \mathrm{O}_{4}$ : C, 61.24; H, 6.17 . Found: C, 61.46; H, 6.12.

$\boldsymbol{\alpha}, \boldsymbol{\alpha}$ '-Di[(4-bromo-1-butoxy)phenyl]-1,4-diisopropylbenzene (3). Using the procedure given above for the preparation of 2 but with 1,4-dibromobutane $(11.9 \mathrm{~mL}, 101 \mathrm{mmol})$ instead of 1,3dibromopropane, the crude product was obtained. After recrystallization from hexanes, $8.01 \mathrm{~g}$ (90\%) of compound 3 with mp $94-95{ }^{\circ} \mathrm{C}$ (lit. mp 105-107 $\left.{ }^{\circ} \mathrm{C}^{1}\right)$ was realized. ${ }^{1} \mathrm{H}$ NMR $(300 \mathrm{MHz}$, $\left.\mathrm{CDCl}_{3}\right) \delta_{\mathrm{H}}: 1.63\left(\mathrm{~s}, 12 \mathrm{H}, \mathrm{CH}_{3}\right), 1.86-1.98\left(\mathrm{~m}, 4 \mathrm{H}, \mathrm{CH}_{2}\right), 2.00-2.12\left(\mathrm{~m}, 4 \mathrm{H}, \mathrm{CH}_{2}\right), 3.48(\mathrm{t}, J=6.6$ $\left.\mathrm{Hz}, 4 \mathrm{H}, \mathrm{CH}_{2}\right), 3.96$ (t, $\left.J=6.0 \mathrm{~Hz}, 4 \mathrm{H}, \mathrm{CH}_{2}\right), 6.74-6.82$ (m, 4H, ArH), 7.07-7.15 (m, 8H, ArH).

$\boldsymbol{\alpha}, \boldsymbol{\alpha}$ '-Di[(5-bromo-1-pentoxy)phenyl]-1,4-diisopropylbenzene (4). Using the procedure given above for the preparation of 2 but with 1,5-dibromopentane $(13.7 \mathrm{~mL}, 101 \mathrm{mmol})$ instead of 1,3dibromopropane, the crude product was obtained. After recrystallization from hexanes, $5.56 \mathrm{~g}$ $(60 \%)$ of compound 4 with $\mathrm{mp} 77-79^{\circ} \mathrm{C}$ (lit. mp 83-85 $\left.{ }^{\circ} \mathrm{C}^{1}\right)$ was obtained. ${ }^{1} \mathrm{H} \mathrm{NMR}(300 \mathrm{MHz}$, $\left.\mathrm{CDCl}_{3}\right) \delta_{\mathrm{H}}: 1.58-1.67\left(\mathrm{~m}, 16 \mathrm{H}, \mathrm{CH}_{3}\right.$ and $\left.\mathrm{CH}_{2}\right), 1.74-1.86\left(\mathrm{~m}, 4 \mathrm{H}, \mathrm{CH}_{2}\right), 1.87-1.99\left(\mathrm{~m}, 4 \mathrm{H}, \mathrm{CH}_{2}\right)$, $3.43\left(\mathrm{t}, J=6.9 \mathrm{~Hz}, 4 \mathrm{H}, \mathrm{CH}_{2}\right), 3.94\left(\mathrm{t}, J=6.3 \mathrm{~Hz}, 4 \mathrm{H}, \mathrm{CH}_{2}\right), 6.75-6.82$ (m, 4H, ArH), 7.08-7.16 (m, 8H, ArH).

Corral (5). A mixture of $0.50 \mathrm{~g}(0.85 \mathrm{mmol})$ of $2,0.29 \mathrm{~g}(0.85 \mathrm{mmol})$ of bisphenol 1 and $1.94 \mathrm{~g}$ (5.94 mmol of $\mathrm{Cs}_{2} \mathrm{CO}_{3}$ in DMF $(40 \mathrm{~mL})$ was stirred at $50{ }^{\circ} \mathrm{C}$ for 5 days. The DMF was evaporated in vacuo and the residue was taken up in $\mathrm{CH}_{2} \mathrm{Cl}_{2}$. The solution was washed with $5 \%$ aq. $\mathrm{HCl}(250 \mathrm{~mL})$, dried over $\mathrm{MgSO}_{4}$, and evaporated in vacuo. The crude product was stirred vigorously in hexanes overnight and filtered to produce $0.47 \mathrm{~g}(71 \%)$ of desired compound 5 with mp 107-108 ${ }^{\circ} \mathrm{C}$ (lit. mp 268-270 ${ }^{\circ} \mathrm{C}^{2}$ ). ${ }^{1} \mathrm{H} \mathrm{NMR}\left(500 \mathrm{MHz}, \mathrm{CDCl}_{3}\right) \delta_{\mathrm{H}}: 1.60-1.68$ (m, 24H, $\mathrm{CH}_{3}$ ), 2.22 (t, $J=6.0 \mathrm{~Hz}, 4 \mathrm{H}, \mathrm{CH}_{2}$ ), 4.08-4.14 (m, 8H, $\mathrm{CH}_{2}$ ), 6.75-6.83 (m, 6H, ArH), 7.08-7.15 $(\mathrm{m}, 18 \mathrm{H}, \mathrm{ArH}) .{ }^{13} \mathrm{C} \mathrm{NMR}\left(126 \mathrm{MHz}, \mathrm{CDCl}_{3}\right) \delta_{\mathrm{C}}: 29.4,30.8,41.8,64.3,113.7,113.8,126.2$, 126.3, 127.7, 127.8, 143.0, 143.1, 147.8, 147.9, 156.6, 156.6. Anal. Calcd for $\mathrm{C}_{54} \mathrm{H}_{60} \mathrm{O}_{4}$ : C, 83.90; H, 7.82. Found: C, 83.84; H, 8.26.

Corral (6). Solution A containing $2.70 \mathrm{~g}(8.11 \mathrm{mmol})$ of bisphenol 1 in DMF $(60 \mathrm{~mL})$ and Solution B containing $5.00 \mathrm{~g}(8.11 \mathrm{mmol})$ of 3 in DMF $(60 \mathrm{~mL})$ were prepared. Using two syringe pumps, Solution A and Solution B were added simultaneously to a stirred mixture of 
$18.50 \mathrm{~g}(56.8 \mathrm{mmol})$ of $\mathrm{Cs}_{2} \mathrm{CO}_{3}$ in $\mathrm{DMF}(150 \mathrm{~mL})$ over a 5 -hour period. The mixture was stirred at $50{ }^{\circ} \mathrm{C}$ for 5 days. The DMF was evaporated in vacuo and the residue was taken up in $\mathrm{CH}_{2} \mathrm{Cl}_{2}$. The solution was washed with $5 \%$ aq. $\mathrm{HCl}(250 \mathrm{~mL})$, dried over $\mathrm{MgSO}_{4}$, and evaporated in vacuo. A suspension of the resulting solid was stirred in $\mathrm{MeOH}$ overnight and filtered to produce $6.36 \mathrm{~g}(98 \%)$ of target compound 6 with mp 195-197 ${ }^{\circ} \mathrm{C}$ (lit. mp 241-245 ${ }^{\circ} \mathrm{C}^{1}$ ). ${ }^{1} \mathrm{H}$ NMR (500 $\left.\mathrm{MHz}_{\mathrm{CDCl}}\right) \delta_{\mathrm{H}}: 1.60-1.68\left(\mathrm{~m}, 24 \mathrm{H}, \mathrm{CH}_{3}\right), 1.88-1.97\left(\mathrm{~m}, 8 \mathrm{H}, \mathrm{CH}_{2}\right), 3.95-4.02\left(\mathrm{~m}, 8 \mathrm{H}, \mathrm{CH}_{2}\right)$, 6.72-6.80 (m, 6H, ArH), 7.06-7.15 (m, 18H, ArH). $\left.{ }^{13} \mathrm{C} \mathrm{NMR} \mathrm{(126} \mathrm{MHz,} \mathrm{CDCl}_{3}\right) \delta_{\mathrm{C}}: 25.8,26.0$, 26.1, 30.7, 30.9, 41.8, 41.9, 67.2, 67.3, 67.4, 113.7, 113.8, 126.2, 127.7, 142.9, 142.9, 147.9, 147.9, 156.7, 156.8. Anal. Calcd for $\mathrm{C}_{56} \mathrm{H}_{54} \mathrm{O}_{4}$ : C, 83.96; H, 8.05. Found: C, 83.36; H, 8.39.

Corral (7). A mixture of $5.00 \mathrm{~g}(7.76 \mathrm{mmol})$ of 4, $2.70 \mathrm{~g}(7.76 \mathrm{mmol})$ of bisphenol 1, and 17.80 $\mathrm{g}(54.3 \mathrm{mmol})$ of $\mathrm{Cs}_{2} \mathrm{CO}_{3}$ in DMF $(450 \mathrm{~mL})$ was stirred at $50^{\circ} \mathrm{C}$ for 7 days. The DMF was evaporated in vacuo and the residue was taken up in $\mathrm{CH}_{2} \mathrm{Cl}_{2}$. The solution was washed with $5 \%$ aq. $\mathrm{HCl}(250 \mathrm{~mL})$, dried over $\mathrm{MgSO}_{4}$, and evaporated in vacuo. The crude product was recrystallized from $\mathrm{CH}_{2} \mathrm{Cl}_{2}-\mathrm{MeOH}$ to produce $6.38 \mathrm{~g}$ (99\%) of desired compound 7 with $\mathrm{mp}$ 145-148 ${ }^{\circ} \mathrm{C}$ (lit. mp 234-238 ${ }^{\circ} \mathrm{C}^{3}$ ). ${ }^{1} \mathrm{H}$ NMR $\left(500 \mathrm{MHz} \mathrm{CDCl}_{3}\right) \delta_{\mathrm{H}}: 1.51-1.60\left(\mathrm{~m}, 28 \mathrm{H}, \mathrm{CH}_{3}\right.$ and $\mathrm{CH}_{2}$ ), 1.68-1.90 (m, 8H, $\left.\mathrm{CH}_{2}\right), 3.89-3.98\left(\mathrm{~m}, 8 \mathrm{H}, \mathrm{CH}_{2}\right), 6.74-6.80$ (m, 6H, ArH), 7.06-7.15 (m, $18 \mathrm{H}, \mathrm{ArH}) .{ }^{13} \mathrm{C} \mathrm{NMR}\left(126 \mathrm{MHz}, \mathrm{CDCl}_{3}\right) \delta_{\mathrm{C}}: 22.8,29.1,29.1,30.8,30.9,41.8,67.6,113.7$, 113.8, 126.2, 126.2, 127.7, 127.7, 142.8, 147.8, 156.8. Anal. Calc for $\mathrm{C}_{58} \mathrm{H}_{68} \mathrm{O}_{4} \bullet 0.3 \mathrm{CH}_{2} \mathrm{Cl}_{2}$ : C, 81.93; H, 8.09. Found: C, 82.10; H, 8.12.

\section{Electronic and vibrational spectroscopy}

The following chemicals were purchased from Sigma-Aldrich and used as received: anthracene and spectrophotometric grade $\mathrm{CH}_{2} \mathrm{Cl}_{2}$. Stock solutions in $\mathrm{CH}_{2} \mathrm{Cl}_{2}$ were prepared: $1 \times 10^{-5}$ to $1 \times 10^{-3}$ $\mathrm{M}$ for each corral and $5 \times 10^{-5} \mathrm{M}$ for anthracene. The absorbances of the prepared stock solutions were measured using Agilent 8453 UV-vis photodiode array. Beer-Lambert's law was used to determine the molar extinction coefficients and these parameters are tabulated in Table 1.

Solution phase complexes were prepared by mixing stock solutions of each corral (1:1, by volume) with a constant final concentration $-2.5 \times 10^{-5} \mathrm{M}-$ of anthracene solution. The final concentration of each corral was varied from 0 to $5 \times 10^{-4} \mathrm{M}$. UV-vis absorption spectra of prepared solutions were acquired. Variation of anthracene absorption intensity was monitored as a function of the corral concentration in $\mathrm{CH}_{2} \mathrm{Cl}_{2}$ at $25^{\circ} \mathrm{C}$. The same procedures were followed for solutions prepared for fluorescence measurements. Fluorescence spectra were measured with a LS-55 Perkin-Elmer spectrofluorimeter. For data analysis, wavelengths were chosen where only one of the reactants - anthracene - absorbs or fluoresces and where the variations as a function of the concentration of cyclophane were the largest. A Perkin-Elmer Spectrum One spectrometer was used to record $\mathrm{KBr}$ pellet vibrational spectra ${ }^{12}$ and solid phase ATR-FTIR spectra were recorded with the Perkin-Elmer Spectrum 100 spectrometer. 


\section{Acknowledgements}

This work was supported by Wheaton College start-up funds and NSF-MRI grant-0421228. The research conducted at Texas Tech University was supported by Grant D-0775 from The Welch Foundation.

\section{References}

1. Dalley, N. K.; Kou, X.; Bartsch, R. A.; Kus, P. J. Inclusion Phenom. 2003, 45, 139.

2. Dalley, N.K.; Kou, X.; Bartsch, R. A.; Czech, B. P.; Kus, P. J. Inclusion Phenom. 1997, $29,323$.

3. Bartsch, R. A.; Kus, P.; Dalley, N. K.; Kou, X. Tetrahedron Lett. 2002, 43, 5017.

4. O’Brien, M.; Smalley, R.; Amonge, A.; Raber, S.; Starosota, A.; Buthelezi, T.; Bartsch, R. A. ; Wegiel M. Microchem. J. 2005, 80, 55.

5. Tewari, A. K.; Dubey R. Rev. Bioorg. Med. Chem. 2008, 16, 126.

6. Alcantar, C. G.; Eliseev, A. V.; Yatsimirsky, V. J. Mol. Recogn. 1996, 9, 54.

7. Diederich, F.; Dick, K. J. Am. Chem. Soc. 1984, 106, 8024.

8. Bourson, J.; Pouget, J.; Valeur, B.; J. Phys. Chem. 1993, 97, 4552.

9. http://webbook.nist.gov/chemistry accessed December 16, 2009.

10. NaziruddinKh, M.; Kumar, P.; Garg, R. K.; Patel, B. S.; Zaidi, Z. H. Spec. Lett. 2002, 35, 489.

11. Frisch, M. J.; Trucks, G. W.; Schlegel, H. B.; Scuseria, G. E.; Robb, M. A.; Cheeseman, J. R.; Montgomery, J. A., Jr.; Vreven, T.; Kudin, K. N.; Burant, J. C.; Millam, J. M.; Iyengar, S. S.; Tomasi, J.; Barone, V.; Mennucci, B.; Cossi, M.; Scalmani, G.; Rega, N.; Petersson, G. A.; Nakatsuji, H.; Hada, M.; Ehara, M.; Toyota, K.; Fukuda, R.; Hasegawa, J.; Ishida, M.; Nakajima, T.; Honda, Y.; Kitao, O.; Nakai, H.; Klene, M.; Li, X.; Knox, J. E.; Hratchian, H. P.; Cross, J. B.; Adamo, C.; Jaramillo, J.; Gomperts, R.; Stratmann, R. E.; Yazyev, O.; Austin, A. J.; Cammi, R.; Pomelli, C.; Ochterski, J. W.; Ayala, P. Y.; Morokuma, K.; Voth, G. A.; Salvador, P.; Dannenberg, J. J.; Zakrzewski, V. G.; Dapprich, S.; Daniels, A.D.; Strain, M.C.; Farkas, O.; Malick, D.K.; Rabuck, A.D.; Raghavachari, K.; Foresman, J. B.; Ortiz, J. V.; Cui, Q.; Baboul, A. G.; Clifford, S.; Cioslowski, J.; Stefanov, B. B.; Liu, G.; Liashenko, A.; Piskorz, P.; Komaromi, I.; Martin, R. L.; Fox, D. J.; Keith, T.; Al-Laham, M.A.; Peng, C. Y.; Nanayakkara, A.; Challacombe, M.; Gill, P. M. W.; Johnson, B.; Chen, W.; Wong, M. W.; Gonzalez, C.; Pople, J. A., Gaussian 03, Revision B.05, Gaussian, Inc., Pittsburgh, PA, 2003.

12. O’Brien, M. Master of Science Thesis, Western Kentucky University, 2005. 